\title{
15
}

\section{Using SWMM 5 to Develop Wet Weather Operating Strategies in a Large Sewer System}

\author{
Mi Chen, Fang Cheng, Edward Burgess, Gregory Barden, Hunter \\ Kelly and Timothy Fallara
}

The City of Columbus wastewater collection system includes separate sanitary and combined sewers, with interceptor sewers directing flow to two large wastewater treatment plants (WWTPs) through complex flow control structures. The potential benefits of modified system operation during wet weather, including potentially real time control (RTC), has been identified and is being investigated as a means to optimize performance of the collection and treatment facilities. Modeling of system performance helps engineers understand system constraints and simulate RTC operating strategies. SWMM 5 is being used to perform these modeling assessments for the Columbus sewer system.

The City of Columbus is currently updating its system wide sewer model using PCSWMM with the U.S. Environmental Protection Agency's Storm Water Management Model version 5 (USEPA SWMM 5) as the computational engine. SWMM 5 provides a number of advantages for modeling the operating strategies versus previous models of the Columbus system that used SWMM 4.4. In particular, the ability to write control rules directly in SWMM 5 offers a significant advantage for modeling complex hydraulic structures and RTC strategies. One purpose of this study is to test the capability of SWMM 5 to simulate a large scale system with complex control rules and its potential to inform design of the real time control system.

Chen, M., F. Cheng, E. Burgess, G. Barden, H. Kelly and T. Fallara. 2010. "Using SWMM 5 to Develop Wet Weather Operating Strategies in a Large Sewer System." Journal of Water Management Modeling R236-15. doi: 10.14796/JWMM.R236-15.

(C) CHI 2010 www.chijournal.org ISSN: 2292-6062 (Formerly in Dynamic Modeling of Urban Water Systems. ISBN: 978-0-9808853-3-0) 
The Interconnector sewer between the Jackson Pike WWTP and the Southerly WWTP is the central conduit that conveys flow from upstream sewersheds to the WWTPs or to storage at the Whittier Street storm standby tanks (SSTs). In order to optimize wet weather flow capture at the Whittier Street SSTs and at the two WWTPs, operating strategies for the Interconnector sewer were developed using SWMM 5.

In the study, SWMM 5 was applied as a fully dynamic hydraulic model with 1200 pipes, 11 pump stations, 28 orifices and 48 storage or wet wells. Control rules to operate the various gates and pump stations in the system were specified. The SWMM 5 model simulates flows in the Interconnector sewer; the control rules are being iteratively adjusted to achieve an optimal solution. This chapter focuses on the effectiveness of SWMM 5 to perform the large scale complex modeling simulations through evaluation of the model representation and model verification.

\subsection{Introduction}

Maximizing in-line sewer storage and utilization of available wastewater treatment plant capacities with sophisticated wet weather operating strategies are increasingly common in large collection systems to reduce frequency and impact of overflows. An acceptable and efficient approach to find the best operating strategy is applying a sewer model to evaluate wet weather collection system performance. Different modeling software packages, such as InfoWorks, MOUSE, and some in-house developed software (Cavanaugh et al., 2006; Cen and Xi, 2007) have been utilized for optimization of the collection system in various projects. More recently, SWMM 5 has become a popular program for this purpose (Rossman, 2004).

The current version of SWMM 5 incorporates a user-friendly interface and a control rules editor with more flexibility to automatically adjust sewer facilities such as gates and divisions than the previous version of SWMM (Huber and Dickinson, 1988). The improvements in SWMM 5 also make it much more effective and efficient for modelers to visualize model results and perform iterative model simulations in order to find optimal control solutions for the collection system.

The City of Columbus (Figure 15.1) is currently conducting a study to optimize wet weather operation of its existing collection and treatment system to support facility planning and design of capital improvement projects defined in its Ohio EPA-approved wet weather management plan. A detailed sewer collection model — the SSCM 2006 model—is being developed using PCSWMM, 
which uses SWMM 5 as its computational engine. In this model, the operating strategies are refined and enhanced based on the defined wet weather management plan (City of Columbus, 2005) to evaluate system capacity, to optimize performance and to reduce overflows.

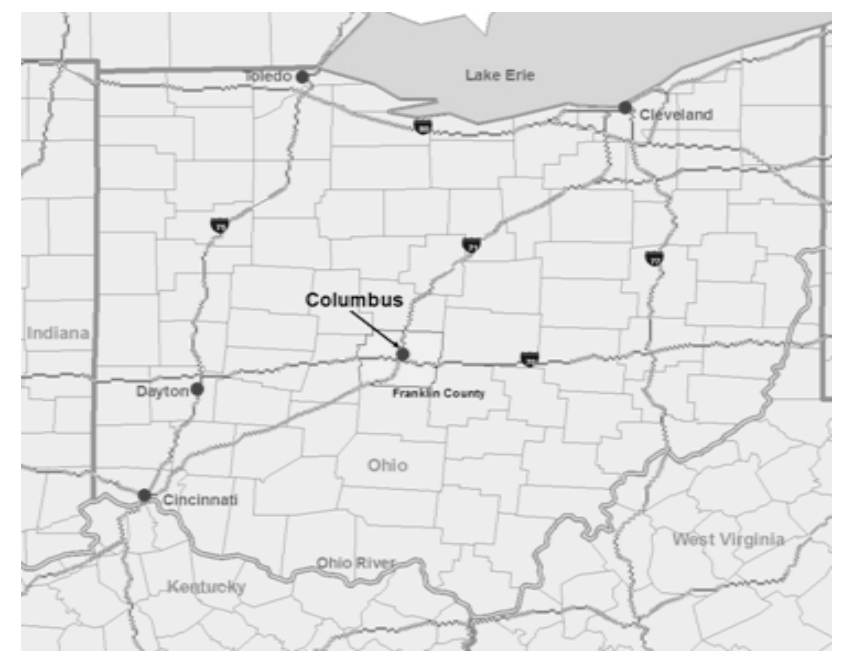

Figure 15.1 Location of Columbus, Ohio.

Using SWMM 5 to simulate a large collection system with complex operating strategies such as proportional-integral-derivative (PID) controller is relatively new. This chapter evaluates the merits of SWMM 5 in the simulation of sophisticated operations in large collection systems. It assesses setting model control rules, model representation, model stability, model reliability, and model improvements.

\subsection{The SSCM 2006 Model Update Project}

\subsubsection{Model History}

The City of Columbus has been developing, updating and refining a computer model of its sewer system since 1987. Originally known as the Columbus Sewer Capacity Study (CSCS) model, it was developed through three phases. The CSCS Phase 3 model was a comprehensive SWMM 4.0 model for the entire collection system, including sewers $\geq 18$ in. $(457 \mathrm{~mm})$ for the separate 
sanitary sewer system and $\geq 15$ in. (381 mm) for the combined sewer system. The CSCS model was calibrated and applied for planning, design and operation purposes. Because of the continuous changes and improvements throughout the sewer system, the city initiated the sewer system capacity model (SSCM) in 2002, which was an update of CSCS Phase 3 to the conditions in 2000. The SSCM 2000 model was developed using SWMM 4.4, used by the city for many years as a tool to support collection system planning, operation, and maintenance. The sewer system operation strategy was initially incorporated in the SSCM 2000 version of the city's sewer model. In 2005, the city developed the wet weather management program (WWMP) model, based on the SSCM 2000 model, in order to evaluate the two wastewater treatment plants and the operating alternatives, and to select and implement system controls.

\subsubsection{SSCM 2006 Model Goals and Scope of Work}

Since 2006, the City of Columbus has been developing its current version of the system wide sewer model. This detailed system wide model includes sewers $\geq 12$ in. $(30 \mathrm{~cm})$ for both the separate sanitary and combined sewer systems and tributary storm sewers to evaluate the collection system at a higher resolution than previously. The goals of the SSCM 2006 model are to support consent order compliance to reduce infiltration and inflow (I/I) and eliminate sanitary sewer overflows (SSOs); to evaluate impacts of future development and system expansion on the collection and treatment system; to optimize wet weather operation of existing collection and treatment system; and to support facility planning and design of capital improvement projects in the wet weather management plan.

The SSCM 2006 model (Figure 15.2) has been developed in PCSWMM; it represents the collection and treatment system at 2008. This new model refines catchment resolution to align with the higher resolution pipe network, and also refines wet weather response characteristics and key hydraulic structures. This new model will be calibrated and applied to evaluate proposed capital improvement projects. A subset of the SSCM 2006 model - an operational submodel - is being developed and used to evaluate operating strategies at the first step and will be applied for the real time control system in the future.

The SSCM 2006 model represents the city's large scale complex system with $200 \mathrm{mi}^{2}\left(518 \mathrm{~km}^{2}\right)$ service area and 711000 customers. The model includes 23200 conduits, 30 combined sewer outfalls (CSOs), 55 designed sanitary reliefs (DSRs; conventionally defined as SSOs), two wastewater treatment plants, and 7 large pump stations. Jackson Pike WWTP averages $80 \mathrm{mgd}$ 


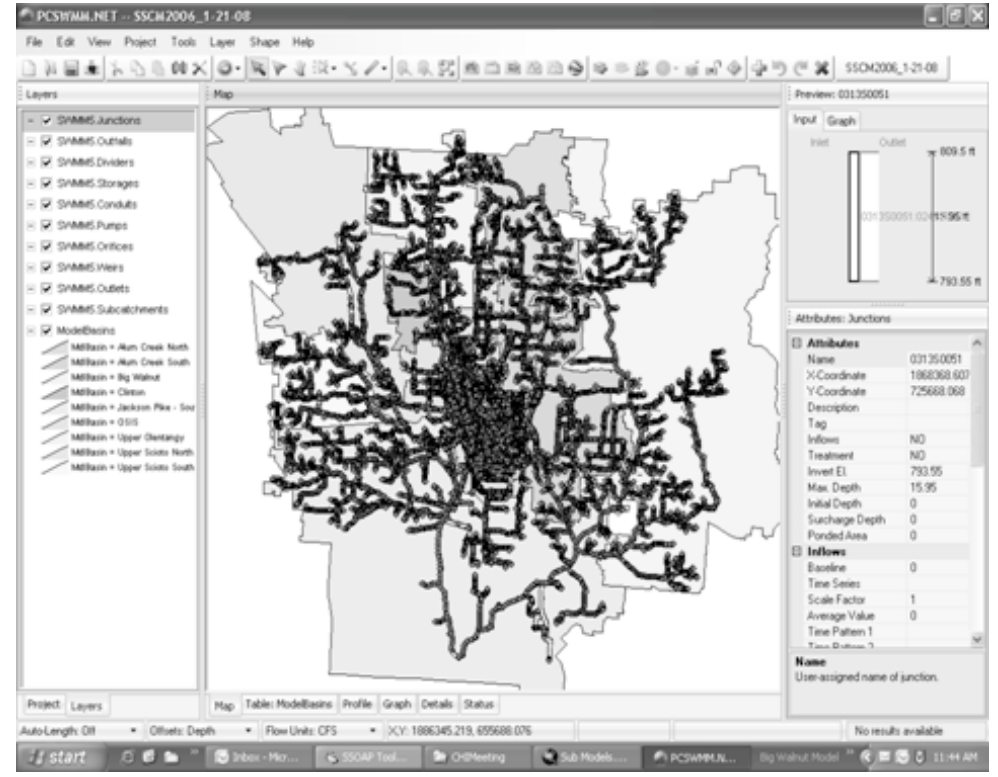

Figure 15.2 SSCM 2006 model in PCSWMM.

to $90 \mathrm{mgd}\left(302800 \mathrm{~m}^{3} / \mathrm{d}\right.$ to $370700 \mathrm{~m}^{3} / \mathrm{d}$ ) and handles $102 \mathrm{mgd}$ to $150 \mathrm{mgd}$ $\left(386100 \mathrm{~m}^{3} / \mathrm{d}\right.$ to $\left.567800 \mathrm{~m}^{3} / \mathrm{d}\right)$ in wet weather; the Southerly WWTP averages $70 \mathrm{mgd}\left(265000 \mathrm{~m}^{3} / \mathrm{d}\right)$ and treats $220 \mathrm{mgd}$ to $330 \mathrm{mgd}\left(832700 \mathrm{~m}^{3} / \mathrm{d}\right.$ to $1249000 \mathrm{~m}^{3} / \mathrm{d}$ ) in wet weather.

\subsubsection{Study of Operating Strategies}

Figure 15.3 shows the extent and relationship between the operational submodel and the SSCM 2006 model. Upstream of the Whittier Street SSTs are the combined sewer areas that contribute most of the flow to the system during wet weather. The Interconnector sewer between Jackson Pike WWTP and Southerly WWTP is the central conduit that conveys flows from the upstream sewer system. By properly operating the Interconnector Sewer, upstream flows can be directed into either the WWTPs or the Whittier Street SSTs.

Initial study of operating strategies focused on the Interconnector sewer and key structures indicated in Figure 15.4. The operating strategies provide guidance for integrated operation of the WWTPs and the collection system. This guidance is based on an evaluation of maximum storage capacity of the Inter- 


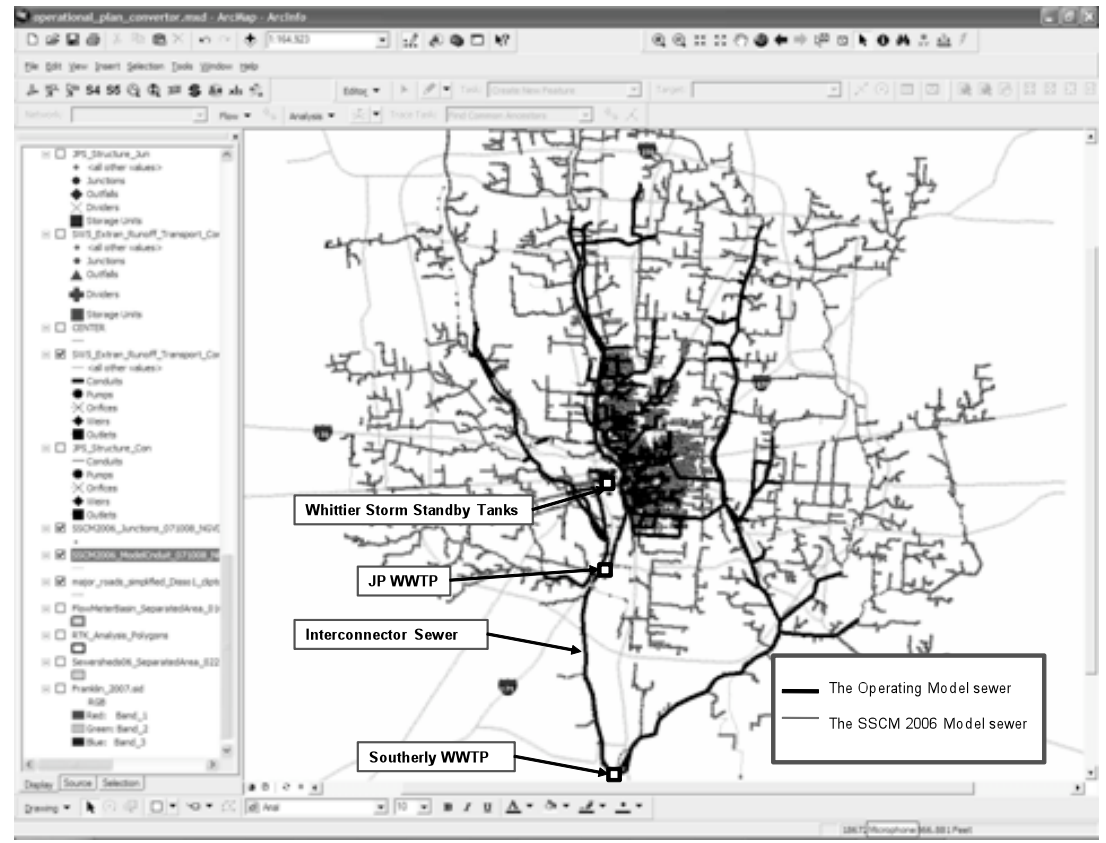

Figure 15.3 Operational sub-model of the SSCM 2006 model.

connector sewer to temporarily store flow from the upstream combined sewers and to maximize treatment capacities at the WWTPs. Using current operating strategies as the starting point, enhanced operating strategies for real time controls to maximize flow capture from the major trunk sewers and interceptors in the entire collection system will be studied.

To efficiently conduct model simulations to find optimal operating control rules under different scenarios, SWMM 5 was applied to the operational submodel. The sub-model (Figure 15.3) includes 1200 pipes, 11 pump stations, 28 orifices, and 48 storage or wet wells. Smaller pipes and upstream sewershed networks are eliminated, using inflow nodes to replace the eliminated sewershed networks. The key structures along the Interconnector sewer (Figure 15.4), whose operations directly affect operation of the WWTPs and overflows from the Whittier Street SSTs, are retained in the operational sub-model. Based on the city's interim Interconnector sewer operational plan, the operational submodel refined the control rules used in the previous WWMP project model and included the new control rules. 


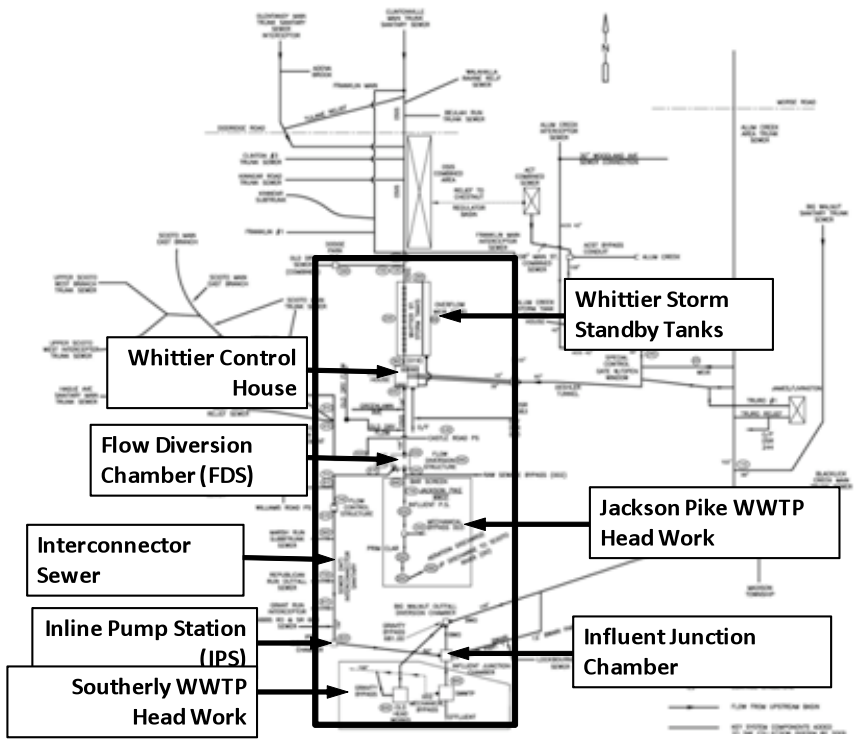

Figure 15.4 Key structures along the Interconnector sewer.

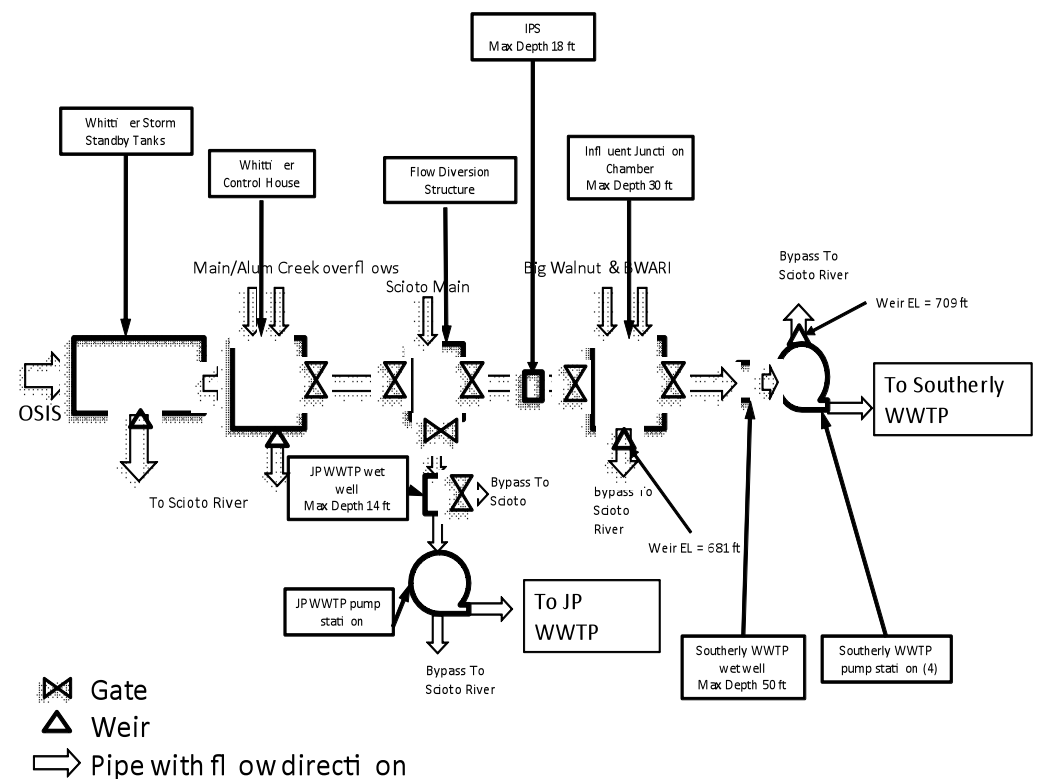

Figure 15.5 Flowchart of operating strategies. 
The flow chart in Figure 15.5 illustrates how key structures in the system are configured. To protect the two WWTPs during wet weather, indicators in the system have been developed through operational experience: the water depth in the Jackson Pike WWTP wet well should be $<14 \mathrm{ft}(4 \mathrm{~m})$, interconnector pump station water depth should be $<18 \mathrm{ft}(6 \mathrm{~m})$, influent junction chamber water depth should be $<30 \mathrm{ft}(9 \mathrm{~m})$, and the water depth in the Southerly WWTP wet well should be $<50 \mathrm{ft}(15 \mathrm{~m})$. Model control rules are being developed to satisfy these conditions for the key structures indicated in Figure 15.5.

\subsection{Discussion}

Because SWMM 5 has been applied to few such large sewer systems with sophisticated operating strategies, its effectiveness for conducting these types of model simulations has been evaluated.

\subsubsection{SWMM 5 Model Representation and Results Display}

SWMM 5 offers a graphical interface where not only the basic pipe and manhole facilities can be easily set up and clearly presented, but also special structures such as gates, weirs, pumps and wet wells. In addition to providing a graphical editor, SWMM 5 improves on prior versions of SWMM by incorporating a flexible and powerful control rules editor. Control rules can be coded in a pop-up dialog. Multi-window display enables modelers to set control rules while viewing the corresponding structures. Figure 15.6 illustrates the control rule dialog.

Multiple sewer profiles can be simultaneously displayed in multiple windows. Profile visualization with the animation function in SWMM 5 facilitates review of flow in different locations. With this function, the consequences of control rule adjustment can be quickly understood by monitoring simulated water depth fluctuations with time across multiple sewer profiles before and after control rules are changed. Figure 15.7 displays hydraulic profiles in four different sewer lines occurring at the same time.

The graphical display features of SWMM 5 help modelers better understand the sewer system response to wet weather, which facilitates development of wet weather operating strategies. During development of the operating strategies, the model was applied to evaluate effects of the new Big Walnut Augmentation/Rickenbacker Inteceptor (BWARI) tunnel that will be located between the Southerly WWTP and the Big Walnut Outfall (BWO) (Figure 15.8). The model was run both with and without the BWARI tunnel included in the system. 


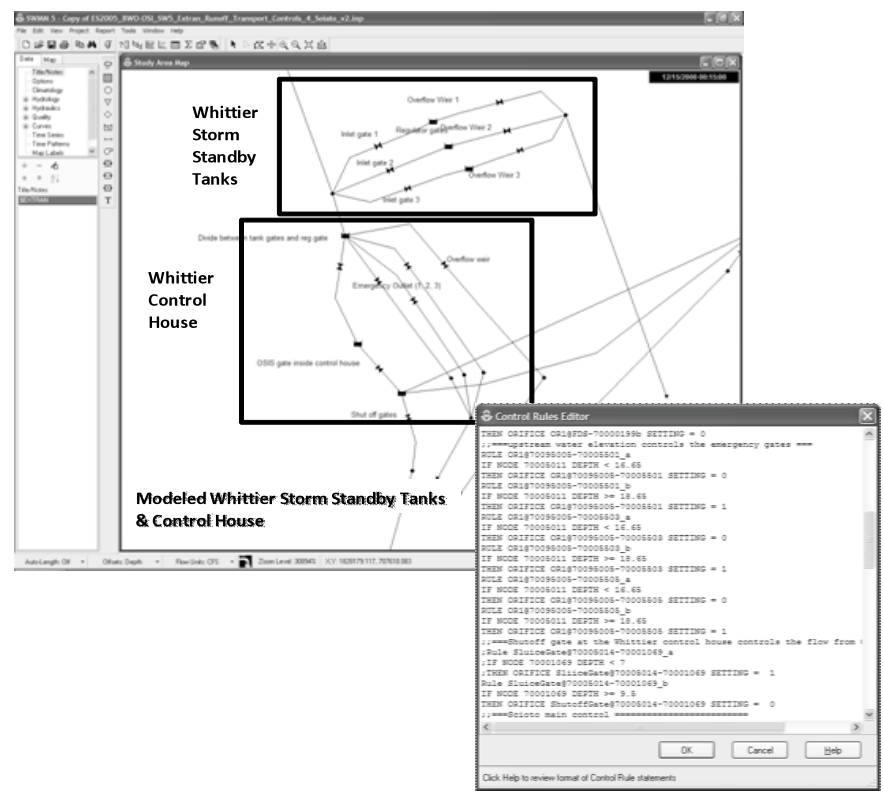

Figure 15.6 Use of Control Rules editor in SWMM 5.

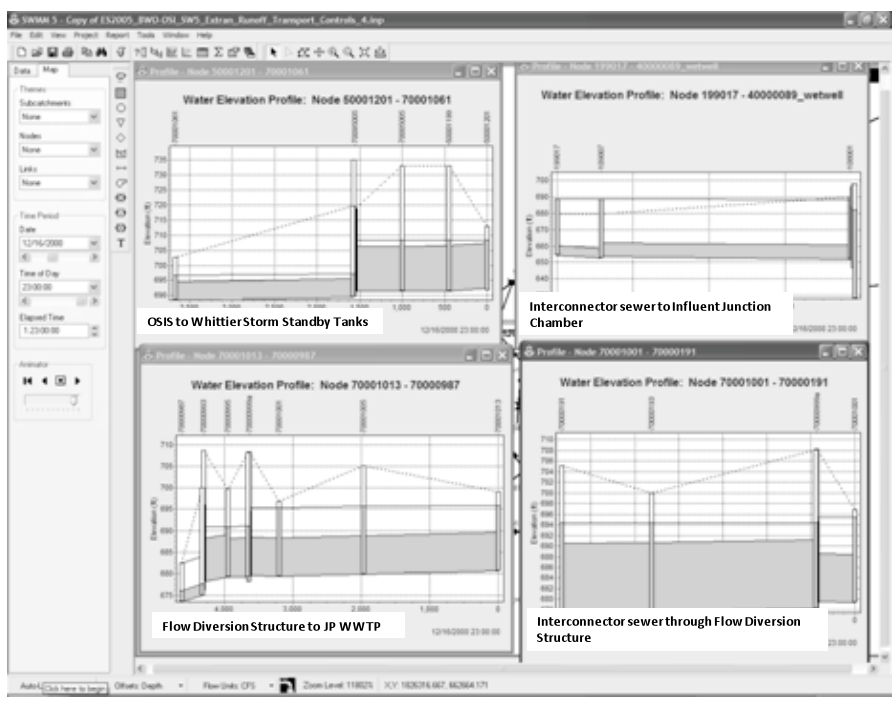

Figure 15.7 Modeled hydraulic profiles showing water depth in the sewer. 


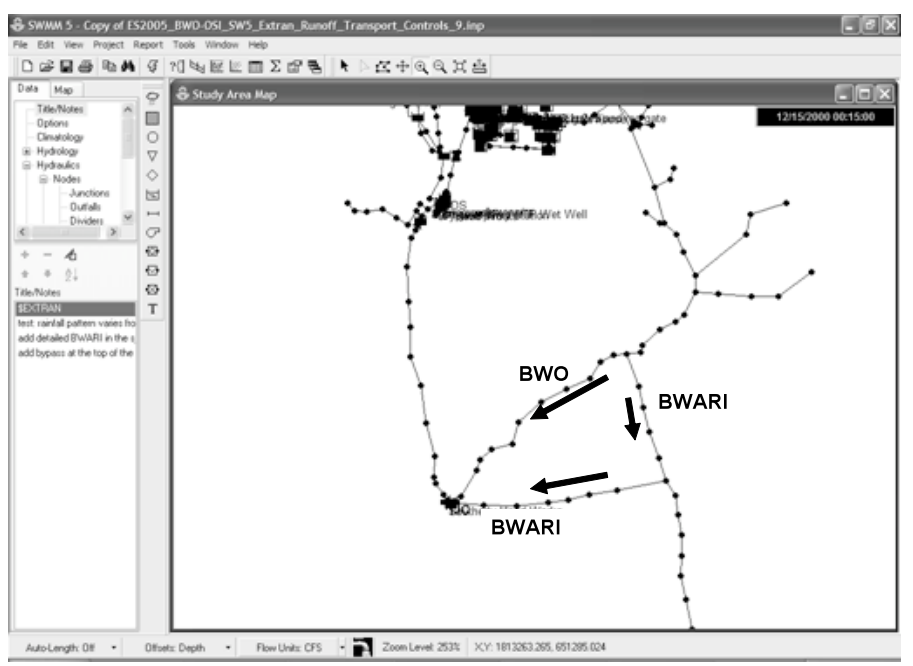

Figure 15.8 BWO and BWARI tunnels represented in the SWMM 5 model.

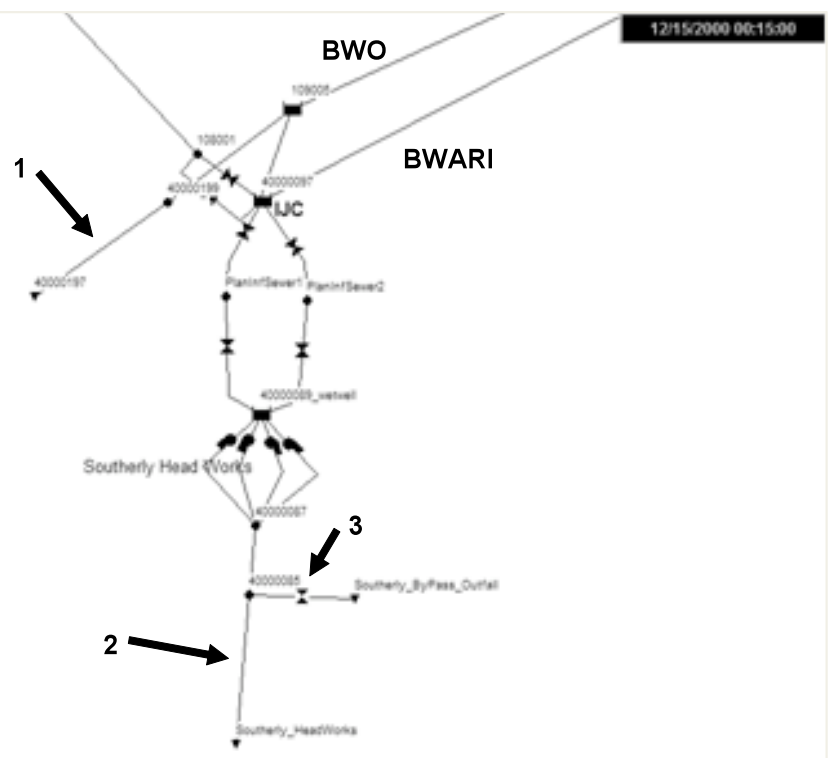

Figure 15.9 Three outfalls at the downstream end of BWO and BWAR in the SWMM 5 model. 
Flows at three outfalls (locations 1,2 and 3) downstream of the two tunnels (Figure 15.9) were compared under the conditions of pre- and post-BWARI installation. The flow at location 1 was expected to decrease because flow from BWO could be routed through the upstream connecting pipe, and stored in BWARI, as the two tunnels (BWO and BWARI) are connected at both the upstream and downstream ends (Figures 15.8 and 15.12). However, the simulation results shown in Figures 15.10 and 15.11 indicate that flows at location 2 and location 3 were not changed under both conditions, and flow at location 1 increased after the BWARI was included in the model, contrary to expectations.

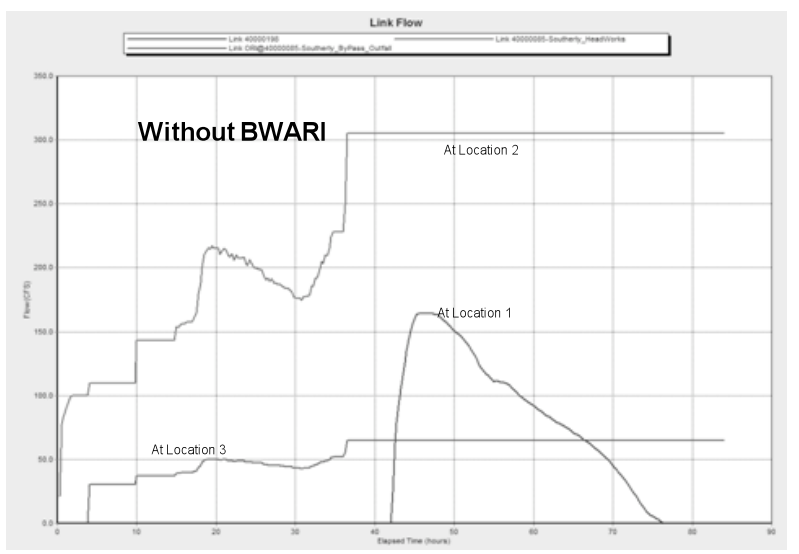

Figure 15.10 Hydrographs at three locations without BWARI.

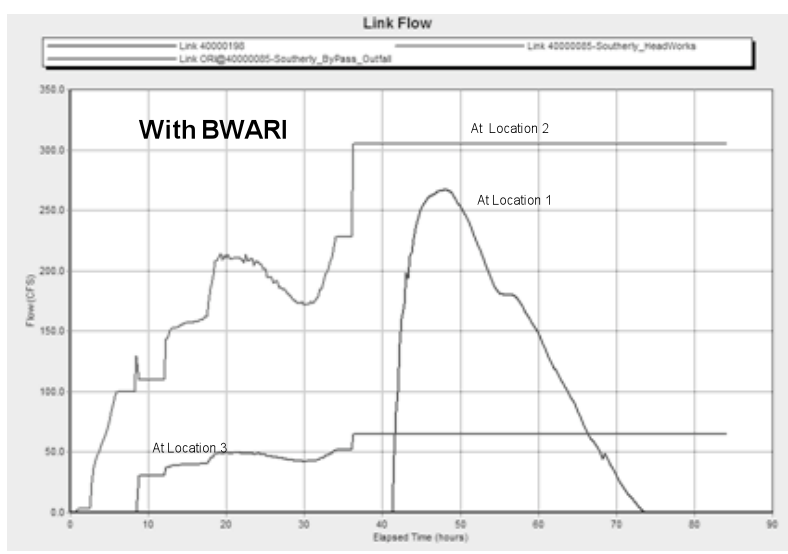

Figure 15.11 Hydrographs at the three locations with BWARI. 


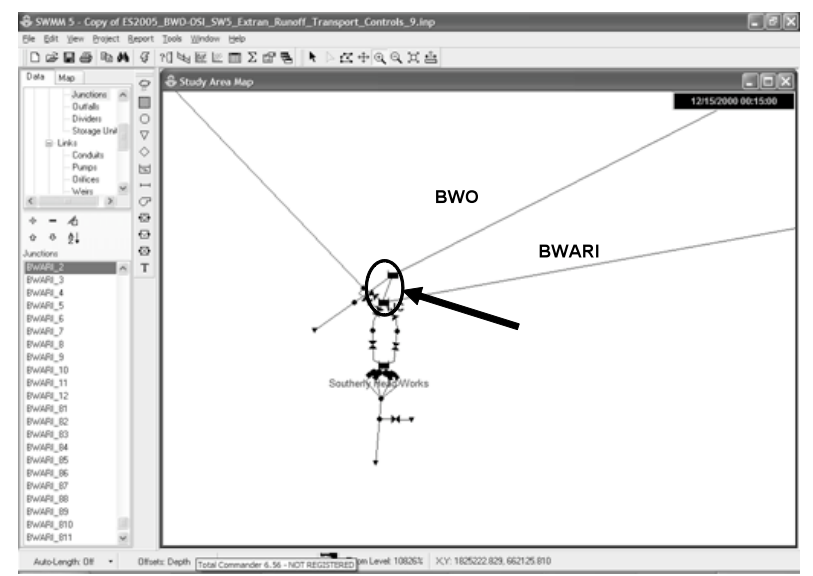

Figure 15.12 Connection at downstream of BWO and BWARI in the SWMM 5 model.

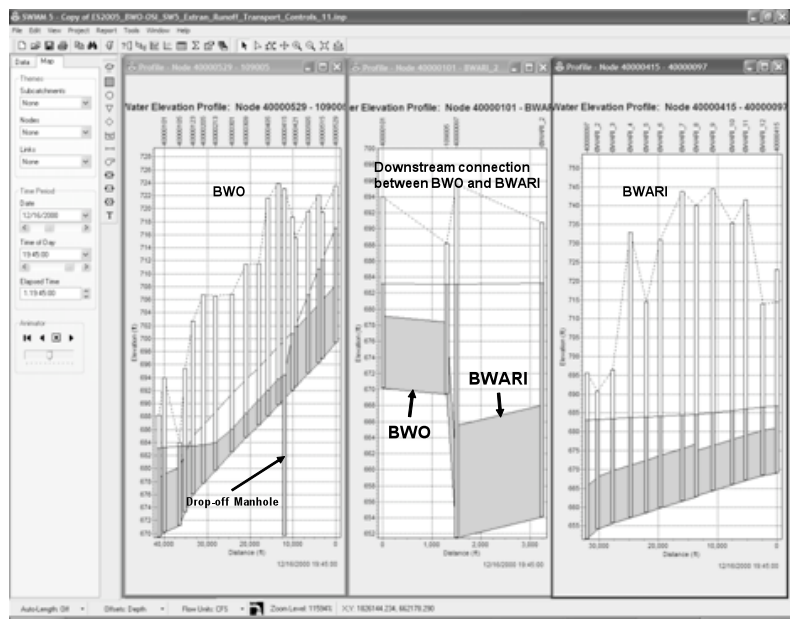

Figure 15.13 Flow in the BWO, BWARI and downstream connection pipe.

By simultaneously observing simulated flow depth fluctuations in the two tunnels and the downstream connection pipe (Figure 15.13 above), engineers realized that with more flow from the upstream reach, the available BWARI storage filled earlier. Eventually the flow depth rose in the connecting pipe to 
an extent causing flow reversal from the BWARI to the BWO. Also of note, BWO flow was routed through BWARI and eventually into the BWO bypass outfall indicated as location 1 in Figure 15.9, while the BWO was only at about half capacity in the middle section. This analysis suggests that gates at both the upstream and downstream connections between BWO and BWARI should be installed in order to maximize the in-line storage of BWARI. The operating rules for these two gates to control the flow in both tunnels and ensure full usage of the available tunnel storage volumes will be further studied during operating strategies development.

During the operating strategies evaluation, the engineers realized that a graphical display or animation of the facility operations that were occurring in the model simulation would be valuable for debugging the control rules and to verify model performance with a higher level of confidence. Future SWMM 5 enhancements should include this functionality.

\subsubsection{SWMM 5 Model Results}

The new model demonstrates that SWMM 5 improves model simulation runtimes, enhances model stability, and provides greater flexibility for handling large scale sewer systems with complex operating procedures, compared with the previous SWMM 4 based model.

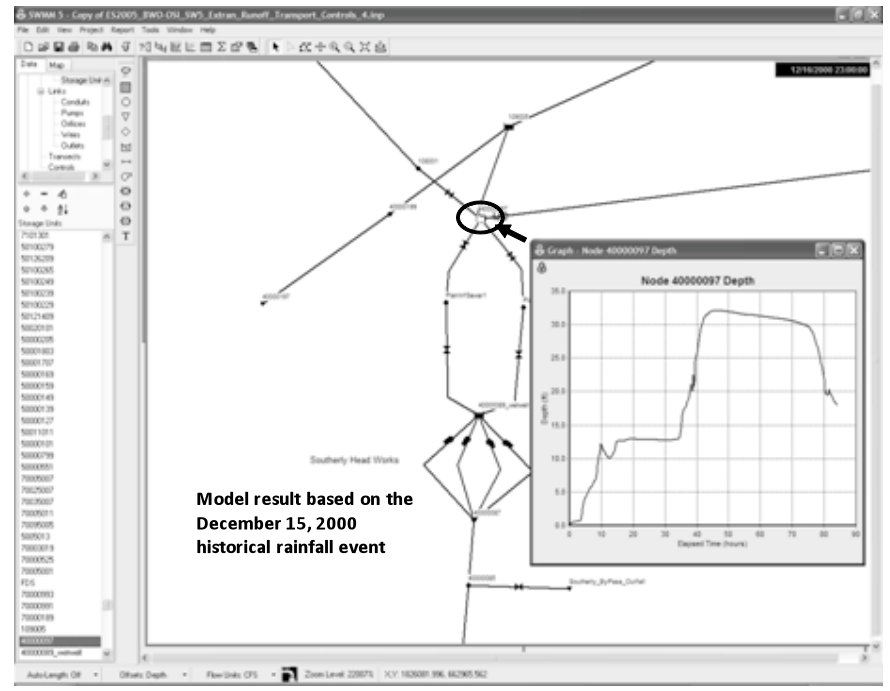

Figure 15.14 Water depth hydrograph at the influent junction chamber. 


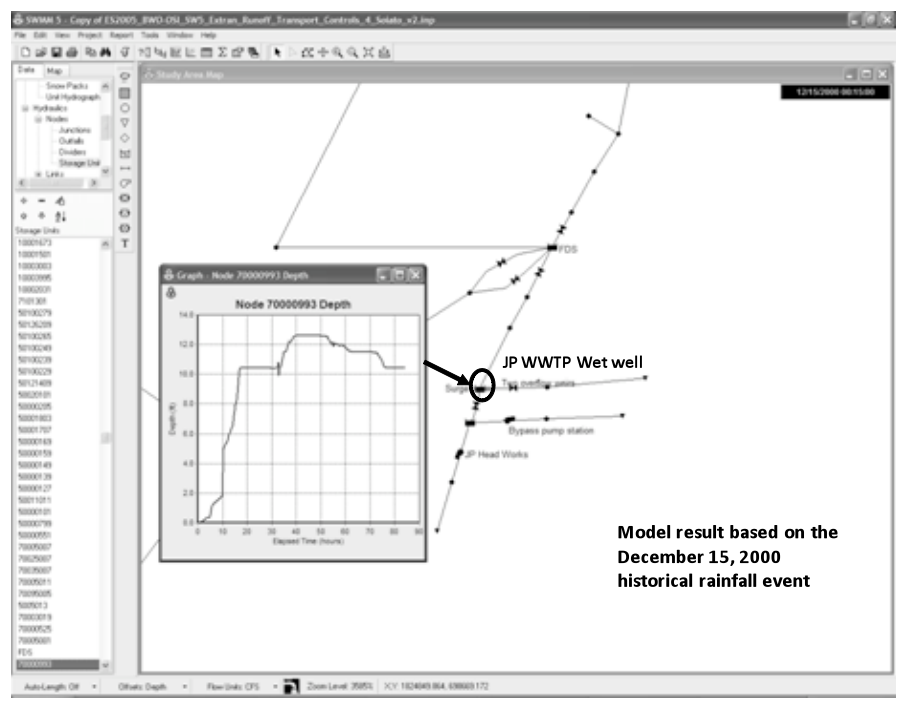

Figure 15.15 Water depth hydrograph at the JPWWTP wet well.

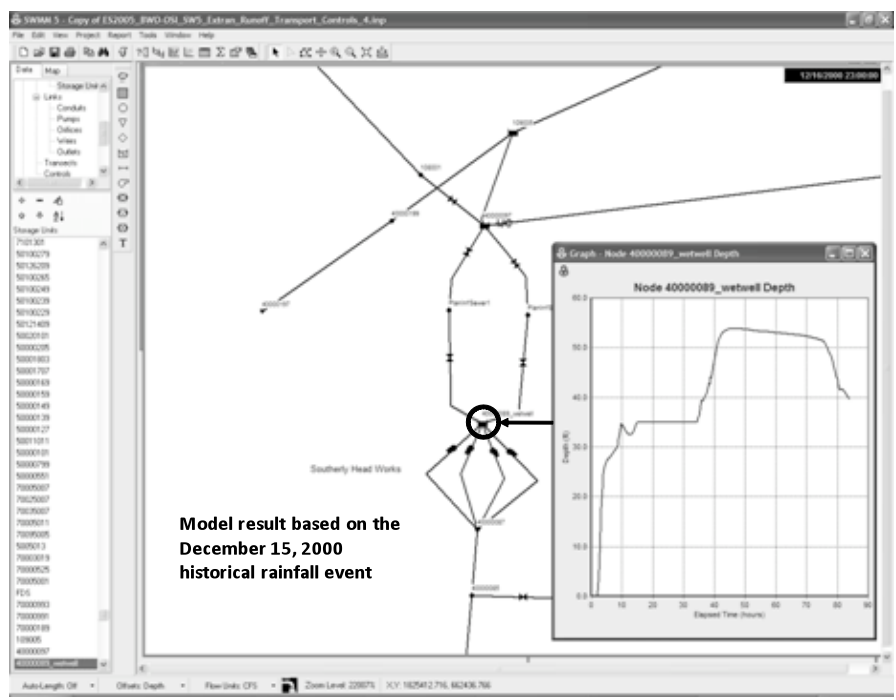

Figure 15.16 Water depth hydrograph at the Southerly WWTP wet well. 
With sufficient care to ensure that the SWMM 5 simulation option parameters are properly established, such as the routing time step and the routing computation method, both acceptable continuity error and model stability can be achieved with acceptably short simulation time. For a $4 \mathrm{~d}$ wet weather simulation with $2 \mathrm{sec}$ time step, elapsed time was $21 \mathrm{~min}(0.25 \mathrm{sec} /$ node/d). Continuity error was $2.6 \%$. The hydraulic model can become instable at complex structures, such as orifices and weirs. The hydrographs in Figures 15.14, 15.15 and 15.16 above display the stable simulated water depth time series plots at selected complex structures along the Interconnector sewer (Figure 15.4 above), which indicate the model stably simulates the complex structures.

\subsubsection{Preliminary Model Verification}

Based on the current control rules in the model, preliminary model verification was conducted by comparing modeled output to observed data. Figure 15.17 displays observed water depth time series at the influent channel of the Whittier SST during January and February 2009. Figure 15.18 shows the flow depth time series obtained from the model simulation for a February 10-11, 2009, rainstorm.

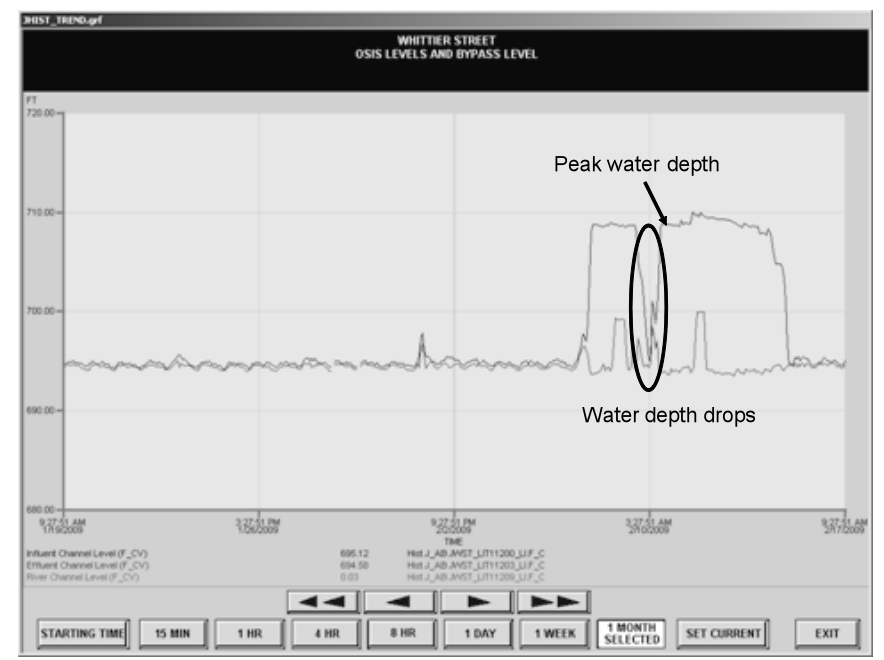

Figure 15.17 Observed flow depth time series at the influent channel of the Whittier storm standby tank. 


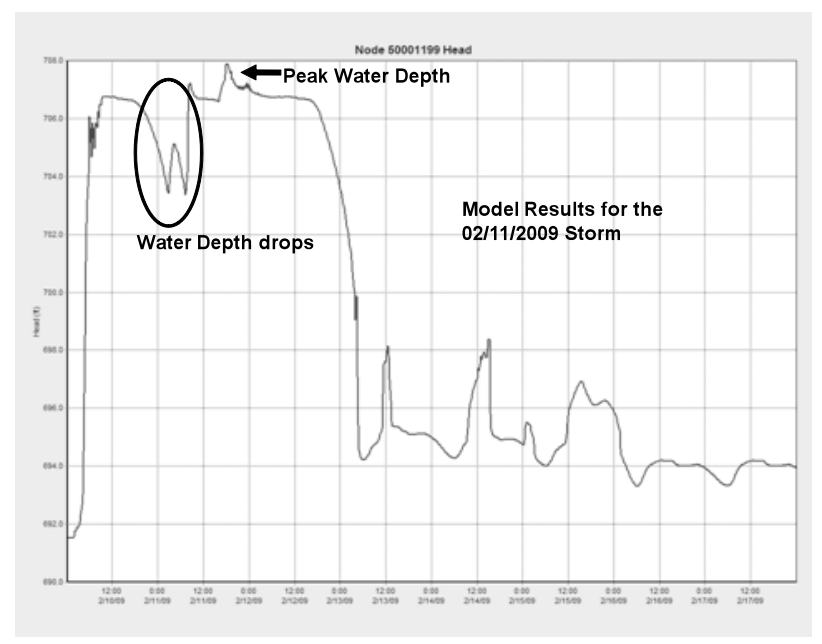

Figure 15.18 Modeled flow depth time series at the influent channel of the Whittier storm standby tank.

Both figures indicate that the peaks of the water depth on February 11, 2009 , are similar. However, the observed data indicates that water depth decreased significantly between February 10 and 11, while only a small decrease was indicated in the model. In addition, the observed water depth persisted near peak levels for several days longer than the modeled depth. These discrepancies have been traced to operating conditions in the field (such as changed gate positions) that were not fully recognized during development of the model control rules.

The preliminary model verification indicates that SWMM 5 is capable of simulating the large scale complex sewer system, but the operating strategies should be refined to improve the model simulations. Because this is an ongoing project, model representation of the operating strategies is being refined. It is expected that model results will be improved and further model verification such as comparisons at the different locations in the system under different wet weather conditions will be conducted as more data are obtained.

\subsection{Conclusions}

SWMM 5 supports successful modeling of complex structures and operations by using control rules and graphical displays to visualize system performance. The Columbus operating strategy model demonstrates good numerical stability 
in SWMM 5 for modeling complex systems. Preliminary operating model simulations demonstrate the feasibility of implementing real time controls in SWMM 5 and that it can be used to find optimal solutions in operation of complex collection systems. More sophisticated real time control strategies will be simulated in forthcoming project phases. It is expected that further insights into using SWMM 5 for this purpose will be gained.

\section{References}

Cavanaugh, E. L., E. D. Loucks, and S. R. Heinz, 2006. Using Long Term Simulation for Improving a Sewer System Overflow Control Strategy. In: World Environmental and Water Resource Congress 2006: Examining the Confluence of Environmental and Water Concerns.

Cen, L. and Y. Xi, 2007. Particle Swarm Optimization for Optimal Flow Control in Combined Sewer Networks-A Case Study. In: Intelligent Control, 2007. ISIC 2007. IEEE 22nd International Symposium.

City of Columbus, Division of Sewerage and Drainage, 2005. Wet Weather Management Plan (WWMP) Report.

Huber, W. C. and R. E. Dickinson, 1988. Storm Water Management Model—Version 4: User's Manual; Cooperative Agreement CR-811607; USEPA; Athens, Georgia.

Rossman, Lewis A., 2004. Storm Water Management Model User's Manual Version 5.0; USEPA Water Supply and Water Resources Division, National Risk Management Research Laboratory, Cincinnati, OH 45268. 